\title{
Clinical outcomes of patients who undergo additional excision after unplanned excision surgery for soft tissue sarcoma.
}

\author{
Kazuhiko Hashimoto*, Shunji Nishimura, Yukiko Hara, Naohiro Oka, Hiroki Tanaka, Ryosuke \\ Kakinoki, Masao Akagi \\ Department of Orthopaedic Surgery, Kindai University Hospital, Osaka-Sayama City, Osaka, Japan
}

\begin{abstract}
Surgeons who operate on benign soft tissue masses that are presumed to be benign often encounter malignancies that require wider excision, a procedure referred to as an 'unplanned excision'. These patients then undergo additional excision after being diagnosed with malignancies. We aimed to investigate the outcomes of patients with soft tissue sarcomas who underwent unplanned excisions of their tumors followed by additional excisions at our institution.

We examined 6 patients with soft tissue sarcomas, 3 men and 3 women, who underwent additional excisions after an unplanned excision between 2004 and 2015 at our hospital. Their mean age was $59.5 \mathrm{y}$, their mean primary tumor size was $9.0 \mathrm{~cm}$, and 3 each had superficial and deep tumors, respectively.

No residual tumor cells were observed in patient specimens following additional excision. None of the patients required plastic reconstructions. The 5-y survival rate was $100 \%$, while the 5 -y local recurrence-free rate was $83 \%$ after 1 patient experienced local recurrence and underwent a second additional resection.

Our data suggest that patients who undergo unplanned excisions should also undergo additional excisions to avoid tumor recurrence.
\end{abstract}

Keywords: Unplanned resection, Additional resection, Soft tissue sarcoma, Prognosis.

Accepted on June 28, 2018

\section{Introduction}

It is not uncommon for a surgeon to operate on a presumed benign soft tissue mass without appropriate preoperative imaging or prior biopsy, and to excise the lesion without paying attention to the surgical margins. Such surgery is referred to as an "unplanned excision", and can present with potential pitfalls when the tumor is found to be a malignancy such as a soft tissue sarcoma [1,2]. As such, unplanned excisions often result in residual malignant tumors that constitute poor prognostic factors [3]. Moreover, flaps are also required because of the additional wide resection that is performed [3]. For these reasons, soft tissue sarcomas should be treated at specific hospitals because of their complexity [4]. However, other previous studies found that unplanned excision does not constitute a poor prognostic factor $[5,6]$, particularly when the additional resection is performed adequately [5]. Another study of foot and ankle sarcomas also concluded that unplanned excisions did not affect survival and resulted in similar functional outcomes as in patients who underwent planned excisions [7]. Thus, whether unplanned excisions cause increased recurrences and affect survival rates remains unclear. To that end, we conducted a retrospective study to determine whether unplanned excisions of soft tissue sarcomas are a poor prognostic factor, and to investigate the management of these sarcomas in such patients.

\section{Patient and Methods}

We retrospectively reviewed 6 patients ( 3 of each sex) with soft tissue sarcomas who underwent unplanned excisions at other institutions followed by additional excisions at our hospital between 2004 and 2015 in a random manner. We examined the recurrence rate and presence of functional impairment after additional resection. Moreover, the relationships between prognosis and features such as size, histology, and type of malignancy were examined.

\section{Results}

Table 1 shows our patients' characteristics and post-resection outcomes. The patents' ages ranged from 11 to 73 y (mean \pm standard deviation (SD), $59.5 \pm 22.7 \mathrm{y}$ ). The tumor site was the thigh in 3 patients and the shoulder, ilium, and elbow in the remaining 3 patients, respectively. The tumor depths were subcutaneous in 3 patients and deep in the remaining 3. Tumor sizes ranged between 4 and $16 \mathrm{~cm}$ (mean $\pm \mathrm{SD}, 9 \pm 5.3 \mathrm{~cm}$ ). The histological grades according to the French Fédération Nationale des Centers de Lutte Contre le Cancer grading system (which ranges from grades I to III) was grade I in 3 
patients and grade II in the remaining 3 [8]. The follow-up period (from initial surgery to the last follow-up) ranged from 6 months to 28 months (mean $\pm \mathrm{SD}, 19.7 \pm 6.95$ months). In terms of adjuvant therapy; chemotherapy was administered to 2 patients (33\%) and radiation therapy (a total dose was 60 Gy) to $1(17 \%)$. The chemotherapy regimen was adriamycin and ifosfamide based on conventional protocols $[9,10]$.

One patient (17\%) had residual tumor cells after initial surgery, and $1(17 \%)$ experienced functional impairment in the form of femoral lateral nerve area perception disorder after undergoing additional resection. 5 of the 6 patients were disease-free at $5 \mathrm{y}$ post additional resection, while 1 (17\%) experienced recurrence. None of the patients experienced metastases and no disease-related deaths occurred. The patient who experienced recurrence after undergoing additional resection was admitted to our hospital after the first recurrence. The patient who had residual tumor tissue after the original unplanned excision did not experience recurrence after additional excision. Moreover, tumor size, depth, and histology did not appear to be associated with tumor recurrence. The 5-y overall survival rate was $100 \%$.

Table 1. Patient characteristics and findings.

\begin{tabular}{|c|c|c|c|c|c|c|c|c|c|c|c|}
\hline $\begin{array}{l}\text { Case } \\
\text { no. }\end{array}$ & Age (y) & Histology & $\begin{array}{l}\text { Malignancy } \\
\text { (FNCLCC) }\end{array}$ & $\begin{array}{l}\text { Time to } \\
\text { additional } \\
\text { resection }\end{array}$ & $\begin{array}{l}\text { Size } \\
(\mathrm{cm})\end{array}$ & $\begin{array}{l}\text { Residual } \\
\text { tumor post- } \\
\text { initial surgery }\end{array}$ & $\begin{array}{l}\text { Recurrenc } \\
\text { e post- } \\
\text { additional } \\
\text { excision }\end{array}$ & Metastasis & Chemotherapy & Radiation & $\begin{array}{l}\text { Outcome } \\
\text { follow-up } \\
\text { period and } \\
\text { recent status }\end{array}$ \\
\hline 1 & 63 & LS & 1 & $1 \mathrm{y}$ & $5 \times 2$ & - & + & - & - & - & $\begin{array}{l}\text { Recurrence (at } \\
6 \text { months after } \\
\text { surgery) CDF }\end{array}$ \\
\hline 2 & 47 & UPS & 2 & 2 months & $15 \times 10$ & - & - & - & + & - & 5-y CDF \\
\hline 3 & 56 & UPS & 2 & 1 month & $16 \times 10$ & - & - & - & + & - & 5-y CDF \\
\hline 4 & 72 & SS & 1 & 2 months & $6 \times 5$ & $\begin{array}{l}+ \text { (recurrent } \\
\text { tumor) }\end{array}$ & - & - & - & - & 5-y CDF \\
\hline 5 & 71 & SS & 2 & 1 month & $12 \times 12$ & - & - & - & - & + & 5-y CDF \\
\hline \multirow[t]{2}{*}{6} & 11 & $\mathrm{AFH}$ & 1 & 2 months & $4 \times 3$ & - & - & - & - & - & 5-y CDF \\
\hline & $\begin{array}{l}\text { Mean: } \\
59.5\end{array}$ & & $\begin{array}{l}\text { 1: } 3 \text { patients } \\
\text { 2: } 3 \text { patients }\end{array}$ & $\begin{array}{l}\text { Mean: } 3.7 \\
\text { months }\end{array}$ & & & & & & & \\
\hline
\end{tabular}

AFH: Angiomatoid Fibrous Histiocytoma; CDF: Continuously Disease-Free; FNCLCC: Fédération Nationale des Centers de Lutte Contre le Cancer (grading system); LS: Liposarcoma; SS: Synovial Sarcoma; UPS: Undifferentiated Pleomorphic Sarcoma.

\section{Discussion}

It remains unclear whether additional resection following an unplanned excision produces a poor prognosis or functional disorders $[2,5]$. Our results suggest that unplanned excisions do not produce such negative outcomes.

In general, achieving a good prognosis in patients with sarcoma requires an adequate wide margin resection [11]. If adequate margins are unachievable, additional resection usually becomes necessary [12]. A previous study suggested that unplanned excisions did not worsen patients' prognoses when additional resections were conducted subsequently [5]. Our results, that showed good patient outcomes, were consistent with those of previous investigations [5,13]. It was also reported that a high histological tumor grade can negatively affect the prognosis [14]. However, the only patient who experienced recurrence in our study had a low-grade tumor; hence, a histological grade did not appear to negatively affect prognosis. Taken together, unplanned excisions do not appear to contribute to poorer prognoses in patients with soft tissue sarcomas.

The influence of adjuvant therapy on patients who undergo unplanned resections of soft tissue sarcomas is not clear $[2,15,16]$. In our study, patients who received adjuvant therapy achieved good outcomes, as they maintained continuous disease-free status. Therefore, adjuvant therapy for such patients may be useful.

Functional disorders often occur following unplanned resections because of the wide margins required [3,5]; this was experienced by only 1 patient in our study. Hence, the site of the tumor may play a role in whether functional disorders develop after additional resection.

Residual tumors after unplanned resections were previously described as being poor prognostic factors [4]. None of the patients had residual tumors following additional excision. Only 1 of our patients underwent repeat resection owing to recurrence; the remainder of the patients achieved good prognoses. Based on these results, it is not clear whether residual tumors worsen prognoses. However, pre-emptively performing additional resection before any recurrence occurs is warranted.

A limitation of our study was the small sample size; hence, a larger number of patients ought to be investigated. The other limitation of the current study is that the histological types were wide-ranging. Further study restricting the histological types will be necessary. 
In conclusion, our data suggest that pre-emptive additional resections ought to be considered in patients who undergo unplanned excisions for soft tissue sarcomas in order to prevent any potential recurrences. We also believe that in case of recurrence, wide additional resections should be promptly added.

\section{Declaration}

\section{Acknowledgement}

We thank Editage (www.editage.jp) for English language editing.

\section{Funding}

This research received no specific grant from any funding agency in the public, commercial, or not-for-profit sectors.

\section{Availability of data and material}

All data and material are available upon request.

\section{Consent for publication}

The patient provided informed consent for publication of this report.

\section{Competing interests}

None.

\section{Authors' contributions}

Data acquisition: Kazuhiko Hashimoto, Shunji Nishimura, Yukiko Hara, Naohiro Oka, Hiroki Tanaka, and Ryosuke Kakinoki.

Data analysis: Kazuhiko Hashimoto, Shunji Nishimura, Naohiro Oka Hiroki Tanaka, Yukiko Hara.

Manuscript preparation: Kazuhiko Hashimoto and Masao Akagi.

\section{References}

1. Khatri VP, Goodnight JE Jr. Extremity soft tissue sarcoma: controversial management issues. Surg Oncol 2005; 14: 1-9.

2. Pretell-Mazzini J, Barton MD Jr, Conway SA, Temple HT. Unplanned excision of soft-tissue sarcomas: current concepts for management and prognosis. J Bone Joint Surg Am 2015; 97: 597-603.

3. Nakamura T, Kawai A, Sudo A. Analysis of the patients with soft tissue sarcoma who received additional excision after unplanned excision: report from the Bone and Soft Tissue Tumor Registry in Japan. Jpn J Clin Oncol 2017; 47: 1055-1059.

4. Charoenlap C, Imanishi J, Tanaka T, Slavin J, Ngan SY, Chander S, Dowsey MM, Goyal C, Choong PF. Outcomes of unplanned sarcoma excision: impact of residual disease. Cancer Med 2016; 5: 980-988.

5. Arai E, Nishida Y, Tsukushi S, Wasa J, Ishiguro N. Clinical and treatment outcomes of planned and unplanned excisions of soft tissue sarcomas. Clin Orthop Relat Res 2010; 468: 3028-3034.

6. Fiore M, Casali PG, Miceli R, Mariani L, Bertulli R, Lozza L, Collini P, Olmi P, Mussi C, Gronchi A. Prognostic effect of re-excision in adult soft tissue sarcoma of the extremity. Ann Surg Oncol 2006; 13: 110-117.

7. Thacker MM, Potter BK, Picher JD, Temple HT. Soft tissue sarcomas of the foot and ankle: impact of unplanned excision, limb salvage, and multimodality therapy. Foot Ankle Int 2008; 29: 690-698.

8. Yamashita K, Kohashi K, Yamada Y, Ishii T, Nishida Y, Urakawa H, Ito I, Takahashi M, Inoue T, Ito M, Ohara Y, Oda Y, Toyokuni S. Osteogenic differentiation in dedifferentiated liposarcoma: a study of 36 cases in comparison to the cases without ossification. Histopathology 2018; 72: 729-738.

9. Benjamin, R.S., Wiernik, P.H., and Bachur, N.R. Adriamycin: a new effective agent in the therapy of disseminated sarcomas. Med Pediatr Oncol 1975; 1: 63-76.

10. Benjamin RS, Legha SS, Patel SR, Nicaise C. Singleagent ifosfamide studies in sarcomas of soft tissue and bone: the M.D. Anderson experience. Cancer Chemother Pharmacol 1993; 31: 174-179.

11. Papagelopoulos PJ, Mavrogenis AF, Mastorakos DP, Patapis P, Soucacos PN. Current concepts for management of soft tissue sarcomas of the extremities. J Surg Orthop Adv 2008; 17: 204-215.

12. Morii T, Aoyagi T, Tajima T, Yoshiyama A, Ichimura S, Mochizuki K. Unplanned resection of a soft tissue sarcoma: clinical characteristics and impact on oncological and functional outcomes. J Orthop Sci 2015; 20: $373-379$.

13. Hanasilo CE, Casadei MS, Auletta L, Amstalden EM, Matte SR, Etchebehere M. Comparative study of planned and unplanned excisions for the treatment of soft tissue sarcoma of the extremities. Clinics (Sao Paulo) 2014; 69: 579-584.

14. Manoso MW, Frassica DA, Deune EG, Frassica FJ. Outcomes of re-excision after unplanned excisions of soft-tissue sarcomas. J Surg Oncol 2005; 91: 153-158.

15. Pretell-Mazzini J, Barton MD Jr, Conway SA, Temple HT. Unplanned excision of soft-tissue sarcomas: current concepts for management and prognosis. J Bone Joint Surg Am 2015; 97: 597-603.

16. Italiano A, Penel N, Robin YM. Neoadjuvant chemotherapy does not improve outcome in resected primary synovial sarcoma: a study of the French Sarcoma Group. Annals Oncol 2009; 20: 425-430. 


\section{*Correspondence to}

Kazuhiko Hashimoto

Department of Orthopedic Surgery

Kindai University Hospital

Osaka-Sayama City

Osaka

Japan 